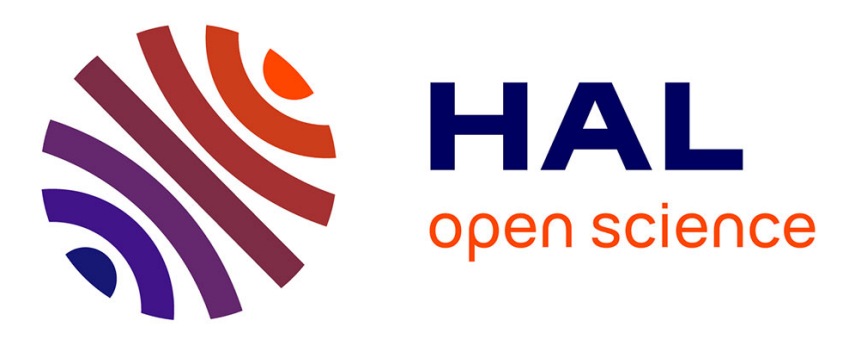

\title{
Mid-infrared supercontinuum generation in hybrid chalcogenide/silicon-germanium waveguides
}

Alberto Della Torre, Milan Sinobad, Remi Armand, Barry Luther-Davies, Pan Ma, Stephen Madden, Sukanta Debbarma, Khu Vu, David Moss, Arnan Mitchell, et al.

\section{To cite this version:}

Alberto Della Torre, Milan Sinobad, Remi Armand, Barry Luther-Davies, Pan Ma, et al.. Mid-infrared supercontinuum generation in hybrid chalcogenide/silicon-germanium waveguides. Australian Conference on Optics, Lasers, and Spectroscopy, Dec 2019, Melbourne, Australia. 10.1117/12.2539913 . hal-02565946

\section{HAL Id: hal-02565946 \\ https://hal.science/hal-02565946}

Submitted on 6 May 2020

HAL is a multi-disciplinary open access archive for the deposit and dissemination of scientific research documents, whether they are published or not. The documents may come from teaching and research institutions in France or abroad, or from public or private research centers.
L'archive ouverte pluridisciplinaire HAL, est destinée au dépôt et à la diffusion de documents scientifiques de niveau recherche, publiés ou non, émanant des établissements d'enseignement et de recherche français ou étrangers, des laboratoires publics ou privés. 


\title{
Mid-infrared supercontinuum generation in hybrid chalcogenide/silicon-germanium waveguides
}

\author{
Alberto Della Torre*a, Milan Sinobad ${ }^{\mathrm{a}, \mathrm{b}}$, Rémi Armand ${ }^{\mathrm{a}}$, Barry Luther-Davies ${ }^{\mathrm{c}}$, Pan $_{\mathrm{Ma}^{\mathrm{c}}}^{\mathrm{c}}$, Stephen \\ Madden $^{\mathrm{c}}$, Sukanta Debbarma ${ }^{\mathrm{c}}$, Khu Vuc ${ }^{\mathrm{c}}$, David J. Moss ${ }^{\mathrm{d}}$, Arnan Mitchell ${ }^{\mathrm{b}}$, Jean-Michel Hartmann ${ }^{\mathrm{e}}$, \\ Jean-Marc Fedeli ${ }^{\mathrm{e}}$, Christelle Monat ${ }^{\mathrm{a}}$, Christian Grillet ${ }^{\mathrm{a}}$ \\ ${ }^{a}$ Université de Lyon, Institut des Nanotechnologies de Lyon (INL), 69131 Ecully, France; \\ ${ }^{\mathrm{b}}$ School of Engineering, RMIT University, Melbourne, VIC 3001, Australia; ' ${ }^{\mathrm{L}}$ aser \\ Physics Center, Australian National University, Canberra, ACT 0100, Australia; ${ }^{\mathrm{d} C e n t r e}$ \\ for Microphotonics, Swinburne University of Technology, Hawthorn, VIC 3122, \\ Australia; ${ }^{e}$ Université Grenoble Alpes, CEA-Leti, 38054 Grenoble Cedex 9, France; \\ *email: alberto.della-torre@ec-lyon.fr
}

\begin{abstract}
We report mid-infrared supercontinuum generation in a silicon germanium-on-silicon waveguide. We show that, by adding a chalcogenide cladding, it is possible to trim a posteriori the waveguide's dispersion profile which, in turn, governs the properties of the generated supercontinuum. In particular, we experimentally show that a shift from anomalous to normal dispersion takes place when a $1.26 \mu \mathrm{m}$ thick cladding layer of $\mathrm{Ge}_{11.5} \mathrm{As}_{24} \mathrm{Se}_{64.5}$ is added. Finally, we show that the group velocity dispersion of the waveguide can be precisely controlled by changing the thickness of the cladding layer.
\end{abstract}

Keywords: Supercontinuum generation; nonlinear optics; integrated optics; mid-infrared; dispersion trimming

\section{INTRODUCTION}

On-chip mid-infrared (mid-IR, between $3 \mu \mathrm{m}$ and $20 \mu \mathrm{m}$ ) supercontinuum (SC) generation is a technological challenge that is promising to have a strong impact in many different fields such as bio imaging, environmental sensors and security [1-5]. The prediction of great nonlinear properties, wide transparency window from 3 to $15 \mu \mathrm{m}$ and CMOS compatibility of germanium have attracted a growing interest toward germanium-based platforms [6,7]. An octave spanning supercontinuum generation up to $8.5 \mu \mathrm{m}$ has been already demonstrated by our group in a $\mathrm{SiGe}$ on $\mathrm{Si}$ waveguide [8-10]. The bandwidth and the coherence properties of the generated SC are mainly determined by the waveguide's dispersion profile. In general, the dispersive properties are set at the design stage and cannot be adjusted once the device has been fabricated. However, fabrication inaccuracies, surface roughness, surface contamination and the presence of defects may lead to a deviation from the targeted dispersion profile. Therefore, post-process mechanisms to post-trim the waveguide dispersion depending on the actual structure produced by fabrication are of great interest. Here we demonstrate mid-IR supercontinuum generation in a SiGe and in a hybrid chalcogenide/SiGe waveguide with shifted dispersion. We show that it is possible to fine tune the dispersion profile a posteriori by changing the chalcogenide cladding thickness, introducing a simple post-processing tool to control the supercontinuum dynamics and its properties.

\section{SUPERCONTINUUM GENERATION AND DISPERSION TRIMMING}

A $7 \mathrm{~cm}$ long $3.75 \times 2.7 \mu \mathrm{m}^{2}$ cross-section $\mathrm{Si}_{0.6} \mathrm{Ge}_{0.4} / \mathrm{Si}$ waveguide was coated with a $1.26 \mu \mathrm{m}$ thick layer of chalcogenide $\mathrm{Ge}_{11.5} \mathrm{As}_{24} \mathrm{Se}_{64.5}$. Numerical simulations show that the group velocity dispersion shifts from anomalous (air clad, fig. 1(a)) to normal (chalcogenide clad, fig. 1(b)) when the coating layer is added. The waveguide, operating in TE single mode, was pumped before and after the deposition of the chalcogenide layer with $\sim 200$ fs pulses at $4 \mu \mathrm{m}$ (air clad) and $4.15 \mu \mathrm{m}$ (chalcogenide clad) delivered from a MIROPA-fs optical parametric amplifier with $63 \mathrm{MHz}$ repetition rate. Fig. 1(c) and 1(d) show the experimental (and theoretical) SC generated out of the air clad and chalcogenide clad waveguide respectively. In the former case the resulting SC, spanning from 2.63 up to $6.18 \mu \mathrm{m}$, shows asymmetric profile and uneven amplitude across the spectrum, both typical of SC generation in the anomalous dispersion regime. In the latter 
case a narrower and smoother spectrum (with a $-30 \mathrm{~dB}$ bandwidth extending from 3.1 to $5.5 \mu \mathrm{m}$ ), typical of SC generation in normal dispersion regime, was obtained. The SC generation process was simulated by numerically solving the nonlinear Schrödinger equation, obtaining a good agreement with experiments. Finally, a numerical analysis of the impact of the chalcogenide thickness on the dispersion was performed, showing that the dispersion properties can be finely tuned with a reasonable chalcogenide thickness resolution of $\approx 100 \mathrm{~nm}$. These results introduce the deposition of a chalcogenide cladding layer as a simple post-processing tool to trim the waveguide's group velocity dispersion depending on the actual structure produced by fabrication.
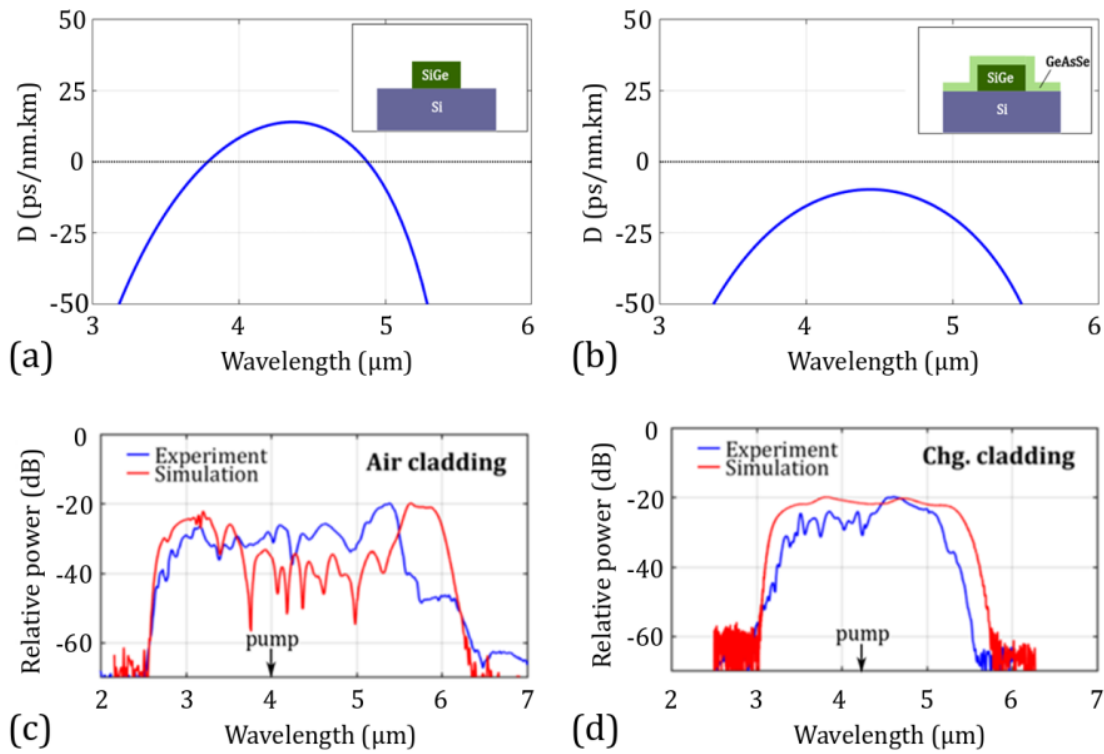

Figure 1. Calculated group velocity dispersion for air clad (a) and chalcogenide clad (b) waveguide with the same $3.75 \times 2.7 \mu \mathrm{m}^{2}$ core cross-section. Experimental (blue) and simulated (red) spectra out of the air cladded (c) and chalcogenide cladded (d) waveguide. The waveguides were pumped by $200 \mathrm{fs}$ pulses at 4 and $4.15 \mu \mathrm{m}$ respectively with $2.35 \mathrm{~kW}$ coupled peak power.

Funding: Agence Nationale de la Recherche (ANR) MIRSiCOMB (ANR-17-CE24-0028), European ERC grant GRAPHICS (648546); We acknowledge the support of the LIA ALPhFA

\section{REFERENCES}

[1] Soref, R., "Mid-infrared photonics in silicon and germanium," Nature Photonics, 4, 495-497 (2010).

[2] Hon, N. K., Soref, R. and Jalali, B., "The third-order nonlinear optical coefficients of Si, Ge, and $\mathrm{Si}_{1-x} \mathrm{Ge}_{x}$ in the midwave and longwave infrared," J. Appl. Phys. 110, 011301 (2011).

[3] Mashanovich, G. Z. et al., "Germanium Mid-Infrared Photonic Devices,” J. Light. Technol. 35, 624-630 (2017).

[4] Hammani, K. et al., "Towards nonlinear conversion from mid- to near-infrared wavelengths using Silicon Germanium waveguides," Opt. Express 22(8), 9667-9674 (2014).

[5] Ettabib, M. A et al., "Broadband telecom to mid-infrared supercontinuum generation in a dispersion-engineered Silicon Germanium waveguide," Opt. Lett. 40(17), 4118-4121 (2015).

[6] Ramirez, J. M. et al., "Low-loss Ge-rich Si $0.2 \mathrm{Ge} 0.8$ waveguides for mid-infrared photonics," Opt. Lett. 42(1), 105-108 (2017).

[7] Ramirez, J. M. et al., "Graded SiGe waveguides with broadband low-loss propagation in the mid infrared," Opt. Express 26(2), 870-877 (2018).

[8] Carletti, L. et al., "Nonlinear optical response of low loss silicon germanium waveguides in the mid-infrared," Opt. Express 23(7), 8261-8271 (2015).

[9] Carletti, L. et al., "Mid-infrared nonlinear optical response of Si-Ge waveguides with ultra-short optical pulses," Opt. Express 23(25), 32202-32214 (2015).

[10] Sinobad, M. et al., "Mid-infrared octave spanning supercontinuum generation to $8.5 \mu \mathrm{m}$ in silicon-germanium waveguides," Optica 5, 360 (2018). 